\title{
The enhancement and reduction of defensive fighting by naloxone pretreatment
}

\author{
MICHAEL S. FANSELOW \\ Dartmouth College, Hanover, New Hampshire \\ and \\ RONALD A. SIGMUNDI \\ Hamilton College, Clinton, New York
}

\begin{abstract}
The effects of the opiate antagonist, naloxone, on the shock-elicited defensive fighting of rats was examined in a single, 200-shock, 56-min session. Early in the session (the first 75 shocks), naloxone enhanced fighting, but late in the session (the second 100 shocks), it depressed fighting. This pattern of data is consistent with the view that naloxone antagonizes an endogenous opiate analgesic system which should reduce the reactions to both shock and the tissue damage produced by numerous fighting encounters.
\end{abstract}

Since the discovery of endogenous opiates, a considerable quantity of research has sought to determine the role that these substances play in behavior (Bolles \& Fanselow, 1982; Olson, Olson, Kastin, \& Coy, 1980). One approach to this question is to ascertain the effects of the opiate antagonist naloxone on some behavioral response. One class of responses that appears to be particularly sensitive to this drug is the species-specific defense reactions (Bolles, 1970) of rodents. Under certain conditions, naloxone increases the defensive freezing of rats (e.g., Fanselow \& Bolles, 1979a, 1979b). The effect of the drug on the defensive fighting exhibited by rats shocked in pairs is less clear. McGivern, Lobaugh, and Collier (1981) reported that naloxone produces a reduction in the incidence of defensive fighting, whereas Fanselow, Sigmundi, and Bolles (1980) found that naloxone enhanced this response. Although many methodological differences exist between the two sets of studies, the present paper concentrates on one difference which may be critical in determining the direction of naloxone's effect on this fighting behavior. This variable concerns the number of shocks received by pairs of rats in the fighting paradigm. Fanselow et al. (1980) tested their rats in two sessions of 20 shocks each, while McGivern et al. tested their rats in a single session of 200 shocks and found that naloxone produced a reduction in fighting only during the second 100 shocks. It may be that naloxone can either enhance or reduce the incidence of shock-elicited fighting, depending on the number of shocks that are administered to paired rats.

Address all correspondence to Michael S. Fanselow, Department of Psychology, Dartmouth College, Hanover, New Hampshire 03755. R. A. Sigmundi is now at the Department of Psychology, University of Toronto, Canada. We thank Endo Laboratories for providing the naloxone.
Although the two sets of studies produced contradictory results, both Fanselow et al. (1980) and McGivern et al. (1981, p. 255) interpreted their findings as being consistent with the same theoretical framework, the perceptual-defensive-recuperative (PDR) model of fear and pain (Bolles \& Fanselow, 1980). We will take this opportunity to clarify the relationship between defensive fighting, naloxone, and the PDR model by explaining why the model suggests that the number of shocks in a session may be crucial in determining naloxone's effect. To understand the PDR model, one must bear in mind the multiplicity of reactions engendered by an aversive unconditioned stimulus (US). These reactions can be divided into three general categories: (1) Withdrawal reflexes-behaviors that are elicited directly by the aversive US. (2) Recuperative behaviors-responses that are elicited not directly by the US, but by tissue damage and irritation which may be caused by the US; they should occur only if the situation has resulted in such damage. (3) Defensive responses-reactions elicited not by the US or tissue damage, but by conditioned aversive stimuli (Fanselow, 1980). Defensive responses occur to the extent that the aversive US supports Pavlovian fear conditioning.

Given that an aversive US controls, either directly or indirectly, the above three response categories, any endogenous analgesic action that reduces the nociceptiveness of the US and of resulting tissue damage can also reduce the incidence of withdrawal, recuperative, and defensive behaviors. Specifically, the PDR model suggests that fear will activate the animal's analgesic systems to reduce nociception and modulate these behaviors. An opiate antagonist, such as naloxone, should have the opposite effect-that of enhancing all three response categories. ${ }^{1}$

For evidence to support this analysis, first consider 
the withdrawal reflexes to an aversive US. Many researchers have shown that opiate antagonists enhance withdrawal reflexes to aversive USs in the presence of fear cues (see Bolles \& Fanselow, 1982, for a review). In the case of recuperative behaviors produced by tissue damage, Fanselow and Baackes (1982) have shown that opiate antagonists enhance Formalin-induced recuperative behavior in the presence of fear cues. Finally, naloxone has been shown to enhance two different defensive behaviors, freezing (Fanselow \& Bolles, 1979a) and defensive fighting (Fanselow et al., 1981; Gorelick, Elliot, \& Sbordone, 1981; Puglisi-Allegra \& Oliverio, 1981).

While naloxone can enhance all three categories of reactions to an aversive US, in most of our testing situations the shock itself is not prolonged or severe enough to produce tissue damage and recuperative behavior. So we usually observe only that naloxone enhances withdrawal reflexes and defensive behaviors. However, it may be that the numerous shocks administered by McGivern et al. and the concomitant fighting and intense muscular activity resulted in some type of tissue damage. One potential mechanism is as follows: Sustained and vigorous muscular activity is known to result in muscular soreness that is caused by the release of endogenous bradykinin-like polypeptides (Mountcastle, 1974, p. 369). Because fear-induced analgesia would normally suppress reactivity to this nociceptive chemostimulation (Fanselow \& Baackes, 1982), recuperative behaviors would not occur and the rats would go on fighting in response to shock. However, naloxone may antagonize this analgesia, allowing muscular soreness to induce recuperative behaviors that interfere with defensive fighting. In this regard, one should note that naloxone enhances the rat's reaction to bradykinin, while opiates suppress this reaction (Satoh, Kawajiri, Yamamoto, Makino, \& Takagi, 1979). Thus, after a few shocks and in the absence of muscular soreness, naloxone may enhance shock-elicited fighting. After repeated shocks, when the rats are tired and sore, naloxone might reduce the incidence of shock-elicited fighting.

Considerations such as these led us to believe that the number of shocks that are administered in the defensive fighting paradigm may play a critical role in determining whether naloxone will enhance or diminish the incidence of shock-elicited fighting. We examined this possibility by testing rats for shock-elicited defensive fighting in a single long session.

\section{METHOD}

\section{Subjects}

Twelve female rats of Long-Evans descent, weighing between 235 and $258 \mathrm{~g}$, were used. The animals were housed individually, with ad-lib access to food and water. The experiment was conducted during the lighted portion of a 14-/10-h light/dark cycle. For the purposes of testing, the rats were assigned to six weightmatched pairs, with the mean weight difference between members of the same pair being $3.33 \mathrm{~g}$.

\section{Apparatus}

The test chamber was a $23.5-\mathrm{cm}-$ long, 29-cm-wide, and $19.5-\mathrm{cm}$-high conditioning chamber. The front and back walls $(29 \mathrm{~cm})$ were made of stainless steel. The side walls $(23.5 \mathrm{~cm})$ and ceiling were made of clear acrylic plastic. The chamber was placed inside a sound-attenuating chest with a $30 \times 30 \mathrm{~cm}$ clear plastic window for observation. A fan attached to the chest provided ventilation and a background noise level of $74 \mathrm{~dB}$ (C-scale).

The floor of the chamber was composed of 18 stainless steel rods, $2.5 \mathrm{~mm}$ in diameter and spaced $1.5 \mathrm{~cm}$ center to center. Each rod was wired to a Grason-Stadler shock generator/ scrambler, which provided a $.5-\mathrm{sec}, 2.5-\mathrm{mA}$ shock. The chamber was illuminated by a $7.5-\mathrm{W}$ white light bulb attached to the ceiling of the sound-attenuating chest. The bulb was centered $12.5 \mathrm{~cm}$ above the ceiling of the test chamber.

After each session, the chamber was cleaned with a paper towel moistened with a $5 \%$ ammonium hydroxide and tap water solution.

\section{Procedure}

Both rats in a pair were given an ip injection and placed in the observation chamber. After a 3-min adaptation period, shocks were delivered every $15 \mathrm{sec}$ until the pair had received 100 shocks. Then the pair was removed from the chamber, given a second ip injection, and replaced in the chamber. Three minutes later, the pair received a second series of 100 shocks spaced 15 sec apart.

One-half of the pairs were assigned to a naloxone condition and half to a placebo condition. All naloxone injections contained $4 \mathrm{mg} / \mathrm{kg}$ of naloxone hydrochloride dissolved in isotonic saline. All placebo injections consisted of an equivalent volume of the saline vehicle. Thus, each pair of rats received either two naloxone or two saline injections during the course of the study.

An observer, blind to the drug condition, scored a fighting encounter if the pair boxed with one another or lunged toward one another in response to the shock. Contact that was incidental to the general activity elicited by shock was not scored as a fighting encounter. A second observer administered the injections and provided a reliability check on the blind observer. The two observers agreed on $88.2 \%$ of the 200 observations, but only the blind observer's data were used in the statistical analyses.

\section{RESULTS}

The data were grouped into trial blocks, with 25 shocks per trial block. The dependent variable, then, was the percentage of fighting encounters per 25-trial block. These data are presented in Figure 1. They were subjected to a group $X$ trial block trend analysis of variance (Edwards, 1972, pp. 335-346). While the main effect for drug was not significant $[F(1,4)<1]$, the trial-block factor was reliable $[\mathrm{F}(7,28)=9.86, \mathrm{p}<.005]$ and showed a linear increase over trials $[\mathrm{F}(1,28)=67.41$, $\mathrm{p}<.005]$.

Of most importance was the reliable group $X$ trial block interaction $[F(7,28)=3.01, p<.025]$. This interaction had a reliable linear component $[F(1,28)=$ $12.89, \mathrm{p}<.005]$, with the saline pairs showing the greater slope. Naloxone-treated animals engaged in more fighting encounters than did placebo animals on early trials but fewer fighting encounters on later trials. The predicted crossover was obtained.

The first two trial blocks correspond most closely to 


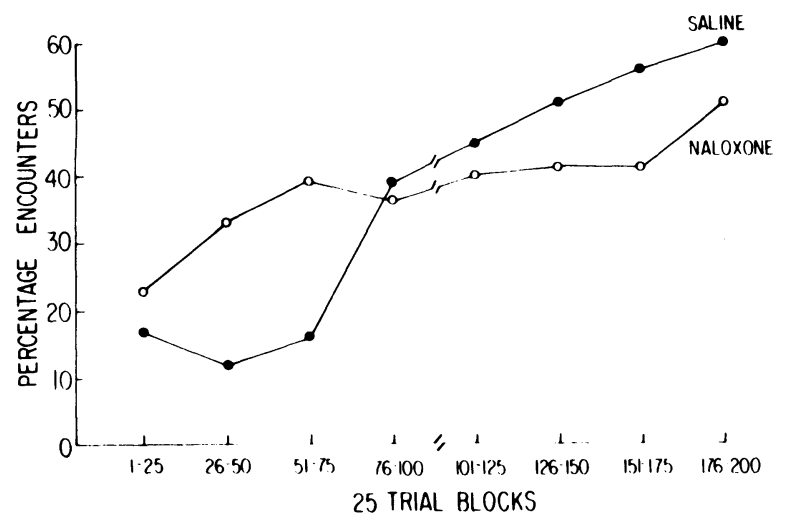

Figure 1. The mean percentage of encounters for naloxone $(4 \mathrm{mg} / \mathrm{kg}$ ) and saline-treated pairs of rats as a function of blocks of 25 shocks.

the data reported by Fanselow et al. (1980); collapsed over those trial blocks, naloxone increased the percentage of encounters $[F(1,28)=5.18, p<.05]$. The last four trial blocks correspond most closely to the data reported by McGivern et al. (1981); collapsed over those trial blocks, naloxone tended to decrease the percentage of encounters $[F(1,28)=5.83, p<.025]$.

\section{DISCUSSION}

Despite several methodological differences, the present study replicated results from the prior work of both Fanselow et al. (1980) and McGivern et al. (1981). Like Fanselow et al., the present study demonstrates that naloxone can enhance defensive fighting in hooded rats. A similar enhancement was reported for albino rats (Gorelick et al., 1981) and C57BL/6 mice (PuglisiAllegra \& Oliverio, 1981). However, with an increase in the number of shocks, naloxone reduced fighting encounters relative to controls, a result that parallels the data reported by McGivern et al.

Defensive fighting is a combination of a defensive behavior and unconditioned reflexes (Blanchard, Blanchard, \& Takahashi, 1977). Therefore, according to PDR theory, naloxone should enhance defensive fighting (that is, of course, provided no recuperative behaviors occur that can interfere with defensive fighting). Since the shocks used in the present study do not produce tissue damage, they do not immediately activate the recuperative system. This explanation of naloxone's effect breaks down when the rat receives over 100 shocks in a single session, for at this point the drug begins to reduce fighting encounters. While the underlying mechanism for this reversal has yet to be isolated, we would like to suggest one possibility: With repeated trials, the sustained vigorous muscular activity involved in the encounters may cause muscular soreness due to the release of bradykinin-like polypeptides with nociceptive properties
(Mountcastle, 1974, p. 369). Such nociceptive chemostimulation has the potential to lead to recuperative behavior that would compete with defensive fighting (Bolles \& Fanselow, 1980; Wall, 1979). ${ }^{2}$ However, there would be no interference with fighting in the saline controls, since fear-induced opiate analgesia is known to suppress the recuperative behavior normally induced by nociceptive chemostimulation (Fanselow \& Baackes, 1982). Naloxonc, by reversing this analgesia, would allow recuperative behavior to compete with fighting. Hence, one might expect to see a naloxone-induced reduction in fighting when the stimulation is prolonged enough to maintain the vigorous muscular activity needed to cause the release of bradykinin-like polypeptides. Satoh et al.'s (1979) report, that naloxone enhances the reaction to bradykinin, is consistent with this suggestion. The presence of a naloxone-reversible endogenous opiate analgesic state is supported by Miczek, Thompson, and Shuster's (1982) finding of a correlation between such an analgesic state and the upright defensive posture (cf. Blanchard et al., 1977).

Let us close with a comment about naloxone's effect on locomotor activity. McGivern et al. (p. 255) suggest that a naloxone-induced suppression of locomotor activity may be responsible for the drug-induced increases in freezing reported by Fanselow and Bolles (1979a). In the same manner, suppression of locomotor activity could also account for the naloxoneinduced decrease in fighting found both in the present experiment and by McGivern et al. While under certain circumstances naloxone may have a suppressive effect on some measures of activity (e.g., Gorris \& Abeelen, 1981; Walker, Berntson, Paulucci, \& Champney, 1981), we feel that such a suppression is an unlikely explanation for naloxone's effect on freezing. First, a naloxoneinduced depression of activity has not been found as consistently as McGivern et al. suggest. In fact, many researchers have found no effect of naloxone on various activity measures (e.g., Carey, Ross, \& Enns, 1981; Fanselow, 1979, Experiment 3; Goldstein, Pryor, Otis, \& Larsen, 1976; Holtzman, 1974; Holtzman \& Jewett, 1973; Stapleton, Lind, Merriman, \& Reid, 1979; Van Der Kooy, LePiane, \& Phillips, 1977). In addition, it has been repeatedly shown that a naloxone-induced suppression of locomotor activity cannot possibly account for this drug's effect on freezing (Fanselow, 1981; Fanselow \& Bolles, 1979a, 1979b). Naloxone affects freezing only if the drug is present during a pairing of a CS and a shock US. Furthermore, naloxone's effect on freezing manifests itself only on postconditioning tests of that CS, and the effect occurs regardless of whether or not naloxone is present during the test (e.g., Fanselow, 1981). On the basis of this evidence, we are inclined to look for some mechanism other than a direct effect of naloxone on activity to explain naloxoneinduced increases and decreases in shock-elicited defensive fighting. 


\section{REFERENCES}

Bass, M. B., Friedman, H. J., \& Lester, D. Antagonism of naloxone hyperalgesia by ethanol. Life Sciences, 1978, 22, 1939-1946.

Blanchard, R. J., Blanchard, D. C., \& Takahashi, L. K. Reflexive fighting in the rat: Aggressive or defensive behavior? Aggressive Behavior, 1977, 3, 145-155.

Bolles, R. C. Species-specific defense reactions and avoidance learning. Psychological Review, 1970, 77, 32-48.

Bolles, R. C., \& Fanselow, M. S. A perceptual-defensiverecuperative model of fear and pain. Behavioral and Brain Sciences, 1980, 3, 291-301.

Bolles, R. C., \& Fanselow, M. S. Endorphins and behavior. Annual Review of Psychology, 1982, 33, 87-101.

Carey, M. P., Ross, J. A., \& EnNs, M. P. Naloxone suppresses feeding and drinking but not wheel running in rats. Pharmacology, Biochemistry and Behavior, 1981, 14, 569-571.

EDWARDs, A. L. Experimental design in psychology research (4th ed.). New York: Holt, Rinehart \& Winston, 1972.

FAnSElow, M. S. Naloxone attenuates rats' preference for signaled shock. Physiological Psychology, 1979, 7, 70-74.

FAnselow, M. S. Conditional and unconditional components of postshock freezing. Pavlovian Journal of Biological Science, 1980, 15, 177-182.

Fanselow, M. S. Naloxone and Pavlovian fear conditioning. Learning and Motivation, 1981, 12, 398-419.

Fanselow, M. S., \& BaAckes, M. P. Conditioned fear-induced opiate analgesia on the Formalin test: Evidence for two aversive motivational systems. Learning and Motivation, 1982, 13, 200-221.

Fanselow, M. S., \& Bolles, R. C. Naloxone and shock-elicited freezing in the rat. Journal of Comparative and Physiological Psychology, 1979, 93, 736-744. (a)

Fanselow, M. S., \& Bolles, R. C. Triggering of the endorphin analgesic reaction by a cue previously associated with shock: Reversal by naloxone. Bulletin of the Psychonomic Society, 1979, 14, 88-90. (b)

Fanselow, M. S., Sigmundi, R. A., \& Bolles, R. C. Naloxone pretreatment enhances shock-elicited aggression. Physiological Psychology, 1980, 8, 369-371.

Goldstein, A., Pryor, G. T., Otis, L. S., \& Larsen, F. On the role of endogenous opioid peptides: Failure of naloxone to influence shock escape thresholds in the rat. Life Sciences, 1976, 18, 599-604.

Gorelick, D. A., Elliot, M. L., \& Sbordone, R. J. Naloxone increases shock-elicited aggression in rats. Research Communication in Substances of Abuse, 1981, 2, 419-422.

Gorris, L. G. M., \& Abeelen, J. H. F. V. Behavioral effects of naloxone in mice from four inbred strains. Psychopharmacology, 1981, 74, 355-359.

Holtzman, S. G. Behavioral effects of separate and combined administration of naloxone and d-amphetamine. Journal of Pharmacology and Experimental Therapeutics, 1974, 189, 51-60.

Holtzman, S. G., \& JewetT, R. E. Stimulation of behavior by cyclazocine: Effects of naloxone. Journal of Pharmacology and Experimental Therapeutics, 1973, 187, 380-390.

McGivern, R. F., Lobaugh, N. J., \& Collier, A. C. Effect of naloxone and housing conditions on shock-elicited reflexive fighting: Influence of immediate prior stress. Physiological Psychology, 1981, 9, 251-256.
Miczek, K. A., Thompson, M. L., \& Shuster, L. Opioidlike analgesia in defeated mice. Science, 1982, 215, 1520-1522.

Mountcastue, V. B. Pain and temperature sensibilities. In V. B. Mountcastle (Ed.), Medical physiology (Vol. 1, 13th ed.). St. Louis: Mosby, 1974.

Olson, G. A., Olson, R. D., Kastin, A. J., \& Coy, D. H. Endogenous opiates: 1979. Peptides, 1980, 1, 365-379.

Puglisi-Allegra, S., \& Oliverio, A. Naloxone potentiates shock-induced aggressive behavior in mice. Pharmacology, Biochemistry and Behavior, 1981, 15, 513-514.

Satoh, M., Kawajiri, S., Yamamoto, M., Makino, H., \& TAKAGI, H. Reversal by naloxone of adaptation of rats to noxious stimuli. Life Sciences, 1979, 24, 685-690.

Sigmundi, R. A., Bouton, M. E., \& Bolles, R. C. Conditioned freezing in the rat as a function of shock intensity and CS modality. Bulletin of the Psychonomic Society, 1980, 15, 254-256.

Stapleton, J. M., Lind, M. D., Merriman, V. J., \& Reid, L. D. Naloxone inhibits diazepam-induced feeding in rats. Life Sciences, 1979, 24, 2421-2426.

Van Der Kooy, D., LePiane, F. G., \& Phillips, A. G. Apparent independence of opiate reinforcement and electrical selfstimulation systems in rat brain. Life Sciences, 1977, 20, 981-986.

Walker, J.M., Bernston, G. G., Paulucci, T.S., \& Champney, T. C. Blockade of endogenous opiates reduces activity in the rat. Pharmacology, Biochemistry \& Behavior, 1981, 14, 113-116.

Wall, P. D. On the relation of injury to pain. Pain, 1979, 6, 253-264.

\section{NOTES}

1. According to the PDR model, it is necessary to have present both conditioned fear stimuli and nociceptive stimulation in order to see a hyperalgesic effect of opiate antagonists. This is because fear is necessary to activate the analgesic system, but the analgesic system can act directly only by reducing nociception from aversive USs or tissue damage. Extensive support for the necessity of the presence of both types of stimuli can be found in Fanselow (1981) and Fanselow and Baackes (1982). All three response categories are increased under these conditions by the hyperalgesic effect of opiate antagonists, just as all three categories increase with the intensity of the aversive US (e.g., reflexes-Bass, Friedman, \& Lester, 1978; recuperative behavior-Fanselow \& Baackes, 1982; defensive behaviorFanselow et al., 1980; and Sigmundi, Bouton, \& Bolles, 1980).

2. There are additional reasons why the recuperative system might be activated. Bruising, injuries, and fatigue might accompany prolonged fighting. Injuries were indicated by bleeding in some of the rats. Fatigue was suggested by the observation that some rats lay on their sides, panting, between shocks. Unfortunately, we are unable at this time to specify the particular recuperative behavior that might interfere with defensive fighting, but see Bolles and Fanselow (1980), Fanselow and Baackes (1982), and Wall (1979) for a description of various recuperative behaviors.

(Manuscript received April 30, 1982; revision accepted for publication June 30,1982 .) 